\title{
Gestantes Soropositivas ao HIV: Maternidade, Relações Conjugais e Ações da Psicologia
}

Marina Simões Flório Ferreira Bertagnoli

Universidade de São Paulo, SP, Brasil.
Marco Antônio Castro Figueiredo

Universidade de São Paulo, SP, Brasil.

Resumo: Mudanças no perfil da epidemia de HIV/Aids ampliaram discussões sobre condições materiais e subjetivas de vida e seu impacto como elemento estruturante da vulnerabilidade à contaminação. Neste contexto, estudar as relações de gênero e a submissão das mulheres aos parceiros é relevante para uma análise da vulnerabilidade entre elas. Este artigo apresenta resultados extraídos de estudo que analisou como mulheres, vulneráveis ao HIV pela própria relação de gênero, lidam com parceiros e com seus direitos reprodutivos. Realizaram-se entrevistas semiestruturadas com dez gestantes soropositivas ao HIV em atendimento pré-natal em ambulatório de ginecologia e obstetrícia especializado no atendimento a pacientes portadores de doenças infectocontagiosas, inserido em um hospital da rede pública de saúde no interior do estado de São Paulo que é considerado referência para a região em que residiam as participantes. Os resultados apontam dificuldades para a distribuição do poder nas relações de gênero como elemento estruturante da vulnerabilidade ao HIV. Entre as participantes, a maioria reconhece a si como vítima da ação de seus parceiros, culpando-os pelo contágio. Aponta-se a necessidade de reestruturar práticas de saúde no atendimento psicológico a mulheres soropositivas, considerando a necessidade de fortalecimento de recursos cognitivos/afetivos para o enfrentamento das vicissitudes do contágio e consequente ruptura com a naturalização como vítimas. Dentre as estratégias para fortalecimento destas mulheres estão: discussão da apropriação do processo do contágio; problematização do aceite tácito da pretensa superioridade masculina e das exigências do parceiro ou da família. O efeito da proposta é reconhecer a passividade feminina como elemento de vulnerabilidade das mulheres e fragilidade das práticas preventivas.

Palavras-chave:Vulnerabilidade em Saúde, HIV, Maternidade. 


\title{
HIV-positive Pregnant Women: Maternity, Marital Relationships and Actions of Psychology
}

\begin{abstract}
Changes in the profile of the HIV/AIDS epidemic have broadened discussions about material and subjective conditions of life and their impact as a structuring element of vulnerability to contamination. In this context, studying gender relations and subjecting women to the partners is relevant to analyze the vulnerability between them. This article presents results from a study that analyzed how women, already vulnerable to HIV, deal with partners and their reproductive rights. Semi-structured interviews were conducted with ten HIV-positive pregnant women in prenatal care at a gynecology and obstetrics outpatient clinic specialized in the care of patients with infectious diseases at a public health hospital and reference to the region in which the participants lived. The results point out difficulties in the distribution of power in gender relations as a structuring element of vulnerability to HIV. Among the participants, most recognize themselves as victims of the action of their partners, blaming them for the contagion. It is pointed out the need to restructure psychological support of seropositive women, considering the need to strengthen cognitive/affective resources to face the vicissitudes of the contagion and consequent rupture with the naturalization as victims. Among the strategies to strengthen these women are: discussion of the appropriation of the contagion process; problematization of the tacit acceptance of the alleged male superiority and of the demands of the partner or family. The effect of the proposal is to recognize female passivity as an element of women's vulnerability and fragility of preventive practices.
\end{abstract}

Keywords: Health Vulnerability, HIV, Maternity.

\section{Las Mujeres Embarazadas que Viven con VIH: Maternidad, Relaciones Maritales y Acciones de Psicología}

Resumen: Los cambios en el perfil de la epidemia de VIH/SIDA han producido discusión más amplia de las condiciones de vida y su impacto como un elemento estructural de la vulnerabilidad a la contaminación. En este contexto, el estudio de las relaciones de género es relevante para el análisis de vulnerabilidad entre las mujeres. Este artículo presenta los resultados del estudio en el que se hicieron entrevistas semiestructuradas con diez mujeres embarazadas con VIH en la atención prenatal en el ambulatorio de ginecología y obstetricia especializadas en el cuidado de pacientes con enfermedades infecciosas. Los resultados muestran dificultades para la distribución de poder en las relaciones de género como un elemento estructurante de la vulnerabilidad al VIH. La mayoría de las participantes se reconocen a sí mismas como víctimas de las acciones de sus maridos, culpándolos del contagio. Apunta a la necesidad de reestructurar la atención psicológica en el cuidado de las mujeres VIH-positivas, teniendo en cuenta la necesidad de fortalecer los recursos cognitivos/afectivos para hacer frente a las vicisitudes de contagio y la consiguiente ruptura con la naturalización como víctimas. Entre las estrategias para el fortalecimiento de estas mujeres son: debate sobre la identificación del proceso de contagio; cuestionamiento de la aceptación tácita de la supuesta superioridad masculina y de los requisitos de los compañeros o familiares. El efecto de la propuesta es reconocer la pasividad de las mujeres como elemento femenino de la vulnerabilidad y fragilidad de las prácticas preventivas.

Palabras claves: Vulnerabilidad en Salud, VIH, Maternidad. 


\section{Introdução}

Mudanças no perfil epidemiológico da epidemia de HIV (Human Immunodeficiency Virus) /Aids determinaram constantes revisões nas formas de compreender e atender a população afetada pela doença e pelos fatores psicossociais atrelados a ela (Figueiredo, 2003). Dentre estas mudanças, a maior incidência de contágio através de relações heterossexuais potencializou, ao longo dos anos 1990, a feminização da epidemia (Parker, \& Camargo, 2000), levando as mulheres a ocupar posição de destaque no cenário da epidemia, orientando a estruturação de algumas estratégias de saúde implementadas no Brasil com o intuito de conter a propagação da epidemia.

Dentre as propostas estruturadas neste contexto, a Política Nacional de Atenção Integral à Saúde da Mulher foi a primeira a propor ampliação de acesso das mulheres aos serviços de saúde prevendo ações que, em tese, deviam promover acolhimento às diversas demandas desta população (Brasil, 2004). Na prática, observa-se, ainda hoje, grande ênfase nas questões reprodutivas, reforçando-se a expectativa social de que as mulheres assumam a função materna.

Constituiu-se desta forma, uma valorização de aspectos biomédicos que pouco avançaram na discussão de aspectos sociais e relacionais; limitaram-se, assim, possibilidades de discussão e proposição de ações que apoiassem o enfrentamento das mulheres a situações específicas como o risco de contaminação por HIV.

A atuação de psicólogos na saúde pública traz marcas ainda profundas do processo de reforma psiquiátrica. Assentada sobre este processo de reconstrução das estratégias de cuidado, a prática psicológica atual busca sua inserção na lógica de trabalho multiprofissional característica do Sistema Único de Saúde (SUS), mas ainda sofre os efeitos de uma formação profissional condicionada pela tradição do modelo clínico hegemônico (Cantele, Arpini \& Roso, 2012; Sales, \& Dimenstein, 2009).

A atuação do psicólogo em serviços de Atenção Primária à Saúde, base do sistema de cuidados, ainda está fortemente organizada em torno deste fazer clínico e individual, normalmente focado exclusivamente no contexto da saúde mental, desconsiderando (ou deixando de atuar de modo ativo) o contexto biossocial (Guareschi, Dhein, Machry, \& Bennemann, 2009).
Considerando os serviços da Atenção Primária à Saúde como um cenário em que produtivas práticas de promoção de saúde (também mental) e de empoderamento de usuários e profissionais podem ser desenvolvidas com a participação e iniciativa de psicólogos, há que se avaliar quais são as dificuldades encontradas por estes profissionais para este novo modelo de exercício profissional.

Dados epidemiológicos apontam que, no período de 1980 a 2015, cerca de 278.960 casos de mulheres com diagnóstico confirmado de contaminação por HIV foram notificados no Brasil, sendo que, deste montante, 166.485 (ou 59,7\% do total) concentravam-se entre mulheres de 20 a 39 anos de idade (Brasil, 2015).

Ainda que seja observada uma tendência à diminuição na proporção de mulheres infectadas com o HIV no país, o impacto social desta situação não pode ser minorado e a atuação de psicólogos, tanto junto a mulheres quanto em parceria com profissionais de outras especialidades, pode promover um movimento de escuta e aproximação a estas usuárias e sua realidade.

Subjacente a dados e números, a consideração dos limites e condicionantes impostos por determinados arranjos e estruturas sociais pode ajudar a reconhecer os efeitos (e vislumbrar as causas) produzidos pela epidemia entre as mulheres.

Inicialmente excluídas da discussão acerca do avanço da Aids, as mulheres só foram incorporadas a esta problemática tardiamente, a partir da constatação de um número crescente de casos entre a população que não pertencia aos denominados "grupos de risco", o que exigiu uma reorientação na análise da doença e na conformação de estratégias para seu controle.

A proposta de uma análise individual, centrada no comportamento desviante pareceu ideal para a transição entre o conceito de "grupo" para a de "comportamento" de risco. A aposta de que o comportamento "anormal" fosse suficiente para explicar a Aids dominou as discussões e o manejo da epidemia por muito tempo, levando a uma análise pouco crítica das relações humanas, incluindo-se aqui as relações de poder, econômicas, sexuais, familiares e de gênero, por exemplo.

O estigma relacionado ao "perfil" das mulheres mais suscetíveis à infecção por HIV mascarou o cenário em que as "mulheres corretas" (que não 
eram prostitutas, por exemplo) viviam, expondo-as não só ao risco, mas à invisibilidade perante os recursos estruturados para oferta de assistência (Villela, \& Monteiro, 2015).

A compreensão superficial das implicações decorrentes da associação do contágio ao comportamento individual construiu uma falsa noção de segurança para aqueles indivíduos que não se identificavam como "desviantes". Em outros termos, a investigação epidemiológica, embora importante e muito útil na compreensão estatística e na análise geral da Aids, mostrou-se restritiva em relação à questão humana, não permitindo a análise e compreensão das variações na significação da sexualidade e suas práticas nas relações e no espaço privado (Parker, 1995).

Fioroni (2005), afirma que o embasamento epidemiológico para a construção de categorias explicativas sobre a Aids acabou cristalizando alguns subgrupos como "protagonistas" desse fenômeno, definindo culpados (gays, usuários de drogas e profissionais do sexo) e vítimas (esposas, filhos e pessoas dependentes de hemoderivados, como os hemofílicos).

O conceito incorporado pela postulação do "comportamento de risco" como recurso para a compreensão da epidemia de Aids foi insuficiente para redimensionar o conflito entre moralidade e imoralidade. A medida em que reforçou o estigma sobre indivíduos com determinados estilos de vida e "comportamentos de risco", essa ideia deixou de atingir o cerne da discussão, falhando em evidenciar que qualquer pessoa pode, ainda que eventualmente expor-se à contaminação (Nascimento, Barbosa \& Medrado, 2005; Villela, \& Monteiro, 2015).

Por estas razões, a perspectiva de "comportamentos de risco" perdeu força, dando lugar a análises que se aproximavam de uma perspectiva mais contextual, valorizando a realidade sociocultural dos indivíduos e das comunidades afetadas.

Parker (1995) afirma que a superação destas postulações está relacionada diretamente à emergência de trabalhos etnográficos sobre a Aids, críticos em relação à "hegemonia das categorias epidemiológicas". Neste contexto, a análise das relações de gênero destacou-se a partir de estudos que relacionaram a epidemia de Aids como processo estruturado por forças sociais que definiam, dentre outros aspectos, $\mathrm{o}$ incremento da suscetibilidade feminina à contaminação por HIV (Villela, \& Monteiro, 2015), questão posteriormente constitutiva do conceito de vulnerabilidade aplicado à compreensão da epidemia.

\section{Relações de gênero e a legitimação social da (i)moralidade}

A análise das relações de gênero permitiu pensar no impacto que algumas estruturas e arranjos sociais produziram no curso da epidemia de Aids e no incremento da suscetibilidade das mulheres à contaminação por HIV. Neste contexto, "examinar a organização sociocultural em relação à cultura sexual” (Parker, 1997, p. 101) tem sido, já há algum tempo, a proposta de alguns pesquisadores, que apontam as dificuldades recorrentes para a negociação de poder encontradas pelas mulheres com seus parceiros, sobretudo nas sociedades latino-americanas. Tal proposta buscou oferecer alternativa ao explícito e tradicional enfoque nos determinantes individuais do comportamento sexual, ampliando a discussão para evitar a tendência a ignorar as estruturas sociais, políticas e econômicas, transversais às relações privadas (Parker, 1995).

O casamento entre homens e mulheres, monogâmico, é das instituições com maior visibilidade na sociedade ocidental, servindo como parâmetro inclusive para as tentativas de aproximação e compreensão de novos arranjos, diferentes da norma. Assumindo funções mais ou menos específicas, homens e mulheres respondem mais que a um projeto pessoal, uma expectativa social na qual está previsto que mulheres cuidam do lar enquanto homens trabalham para prover o lar e a família (Lamoglia, \& Minayo, 2009; Parker, 1995). Obviamente, a inserção da mulher no mercado de trabalho e a crítica feminista operaram no sentido de redistribuir estas funções, permitindo que mulheres se ausentassem de casa para trabalhar e avançar em suas carreiras, enquanto alguns homens passaram a experimentar a divisão das tarefas domésticas.

Não se trata, no entanto, de analisar como se conformam as relações matrimoniais, mas apenas de registrar que, embora esteja em efervescente revisão, a instituição matrimonial ainda se orienta, em linhas gerais, pela divisão dos sexos e pela limitação dos espaços que devem ser ocupados por cada um dos cônjuges.

Lamoglia e Minayo (2009) afirmam que a dominação da mulher pelo homem tem sua raiz na cultura patriarcal, que promove a desigualdade de poder entre os gêneros. A "privacidade" feminina submete a mulher ao homem, dando a ele condi- 
ções de dominar esposa, filhos e o próprio relacionamento com o consentimento da família estendida e da própria sociedade.

Quando se aplica esta lógica à análise da epidemia de Aids, é possível observar que muitas mulheres, acreditando-se "protegidas" pelo casamento, negligenciaram (ou foram obrigadas a negligenciar) práticas preventivas básicas, tais como o uso de preservativo nas relações sexuais uma vez que, sob a ótica de sua posição de passividade e dominação, a conjugalidade pressupõe fidelidade. Pode-se afirmar que a instituição matrimonial alivia, dessa forma, o medo de contaminação por doenças sexualmente transmissíveis ou pelo próprio HIV, parecendo promover imunidade para as "mulheres corretas", que não se envolvem nos já referidos comportamentos de risco.

Essa sujeição ao homem e a seus desejos pode ser explicada pelo fato de que, para muitas mulheres, sua identidade só se viabiliza a partir da relação conjugal e, embora possa provocar revolta e abalar a autoconfiança destas mulheres, a vitimização que sofrem em decorrência da infidelidade masculina é normalmente relevada pelas esposas, preocupadas em manter a segurança social do casamento e em preservar a imagem da família.

\section{Maternidade como exemplo da "função feminina"}

Considerando a discussão sobre como a expectativa social e familiar reforça a submissão feminina, pode-se destacar a expectativa da maternidade como exemplo. Em algumas culturas, tornar-se mãe é uma decorrência natural do casamento para a mulher (Villela, \& Monteiro, 2015) e um evento aguardado com ansiedade pelas pessoas. O posicionamento feminino em relação à decisão de ter ou não filhos pode, inclusive, ser desconsiderado em algumas situações ou influenciado pela obrigatoriedade de dar filhos ao parceiro com que se relaciona (ou aos parceiros com os quais vier a se relacionar).

A possibilidade de negociar a contracepção ou a necessidade de discutir estratégias de prevenção da contaminação por doenças sexualmente transmissíveis (incluindo-se aqui o contágio por HIV) é sufocada em nome da manutenção deste lugar social reservado às mulheres em sua maioria (Ribeiro, Silva \& Saldanha, 2011).

A perversidade desta lógica faz com que as esposas, santificadas pela relação matrimonial, e distanciadas assim da ideia de promiscuidade deixem de poder negociar o uso de preservativos nas relações sexuais dentro do casamento (Parker, 1997; Ribeiro et al., 2011), impedindo-as de estabelecer uma identificação com a condição de outras mulheres (estas consideradas promíscuas), identificadas como responsáveis pelo avanço dos casos de contaminação (Parker, \& Aggleton, 2001).

Definidas como mulheres não promíscuas, as "esposas" (ou aquelas mulheres envolvidas em relacionamentos estáveis) são vistas como incapazes de contaminar seus parceiros e, assim, qualquer tentativa de negociação do uso de preservativo na relação conjugal passa, em tese, a denunciar uma ruptura com este lugar social, expondo a mulher a críticas e à dúvida do marido em relação a sua fidelidade (Ribeiro et al., 2011).

Santos (1998) já afirmava que a forma como a sociedade se organiza para manutenção do poder entre gêneros determina as possibilidades de prevenção e enfrentamento da Aids. Desta forma, a condição feminina parece determinar um incremento na vulnerabilidade ao HIV e um esgotamento das possibilidades para o planejamento da própria vida reprodutiva entre estas mulheres.

O agravo que esta situação constitui a saúde da mulher, no Brasil, é representado por dados epidemiológicos que apontam que, desde 2000 até junho de 2015, foram notificados 92.210 casos de gestantes infectadas com o HIV no país. Entre 2005 e 2014, houve aumento de $30 \%$ no número de casos detectados entre gestantes $(2,0$ casos de gestantes infectadas a cada mil nascidos vivos, em 2005, ante 2,6 casos a cada mil nascidos vivos, em 2014). Interessante notar que, no mesmo período, houve tendência de queda na taxa de detecção de casos entre mulheres (16,3 casos/100 mil habitantes em 2005 e 13,7 casos/100 mil habitantes em 2014, representando uma queda no período de $18,9 \%$ ). Finalmente, o número de casos de transmissão vertical também diminuiu neste período, caindo $33,3 \%$ entre os anos de 2005 e 2014 (Brasil, 2015).

Considerando estes dados, pode-se afirmar que ações profiláticas da transmissão vertical implantadas no país estão surtindo efeitos positivos; além disso, a redução na tendência à infecção por HIV entre mulheres pode ser compreendida como efeito de uma maior conscientização sobre a vivência da própria sexualidade entre elas. 
Contudo, pode-se compreender aumento tão significativo no número de casos de gestantes como indicativo das dificuldades encontradas por mulheres na vivência de sua saúde reprodutiva. Neste contexto, a experiência de vida de cada mulher, seus valores e a forma como cada uma delas é capaz de significar questões como a contaminação por HIV, o adoecimento, sua sexualidade e suas vivências na relação saúde-doença parecem ser determinantes para a compreensão de seu processo de decisão sobre ter ou não filhos, por exemplo (Silva, Alvarenga, \& Ayres, 2006).

Considerando este universo de referências, importa saber como as mulheres, muitas vezes já tão vulneráveis (pela própria relação de gênero) à contaminação pelo HIV, lidam com seus parceiros e, sobretudo, com seus direitos reprodutivos. Apresenta-se, a seguir, um extrato do processo de investigação e dos resultados obtidos em estudo realizado neste contexto.

\section{Método}

\section{Participantes}

Participaram do estudo dez gestantes soropositivas ao HIV, com idades entre 18 e 39 anos. O número de gestações e o momento de diagnóstico da soropositividade ao HIV (se antes ou durante a gestação atual) não foram adotados como critérios de exclusão na amostra.

\section{Local do estudo}

As participantes foram identificadas e recrutadas em um ambulatório de ginecologia e obstetrícia, especializado no atendimento a pacientes portadores de doenças infectocontagiosas em um hospital da rede pública de saúde no interior do estado de São Paulo e referência para a região em que residem as participantes.

Além do atendimento semanal a mulheres portadores de moléstias infectocontagiosas, o ambulatório também desenvolve estratégias diferenciadas para garantir o acolhimento e a adesão ao tratamento entre as gestantes atendidas, incorporando a presença do parceiro/pai às consultas de pré-natal e a testagem sorológica destes homens como recurso profilático e protetivo para mulheres e bebês atendidos.

\section{Procedimentos de coleta de dados}

O contato inicial com as participantes foi realizado no próprio ambulatório, durante o momento de espera pela consulta de pré-natal. Aquelas dispostas a colaborar com o estudo foram informadas sobre os objetivos e etapas da pesquisa, obedecendo às exigências éticas pertinentes. As participantes responderam a um questionário semiestruturado e os relatos foram gravados em áudio mediante autorização expressa das participantes e analisados com o objetivo de explorar os seguintes temas: experiências em relacionamentos conjugais e afetivos; sexualidade; gestação e maternidade; o contágio por HIV; relações familiares e sociais; e experiências de apoio disponíveis dentro da família e também nos serviços de saúde.

A escolha do local para realização da entrevista obedeceu a preferência das participantes, que optaram por realizá-la no próprio serviço de saúde.

\section{Procedimentos de análise}

O conteúdo dos relatos colhidos nas entrevistas foi transcrito, servindo como material para análise. Observações e outros registros, feitos pela pesquisadora durante os encontros com as participantes, também foram considerados como material de apoio para compreensão do repertório de significados utilizado por elas.

Os relatos foram submetidos a processo de análise de conteúdo, organizado em duas fases. Na primeira fase, a ênfase de análise foi dirigida a cada uma das entrevistas e obedeceu às seguintes etapas: leitura inicial do material, que permitiu a organização geral dos sentidos abordados por cada uma das participantes; marcação de trechos singulares ou relevantes para o estudo; seleção de trechos significativos e seu agrupamento por semelhança, com identificação de temas recorrentes nos relatos de cada participante; junção dos trechos em quadros de síntese por conteúdo; inserção de informações subsidiárias para apoiar a contextualização dos relatos de cada participante.

Na segunda fase, a ênfase de análise foi dirigida para a relação entre o conteúdo das entrevistas de todas as participantes, tomando como base todos os quadros de síntese por conteúdo produzidos a partir da análise das entrevistas individuais. Nesta segunda fase, obedeceu-se às seguintes etapas: leitura inicial dos quadros de síntese por conteúdo produzidos na primeira fase; organização, por 
semelhança de conteúdo e contexto, de trechos de diferentes entrevistas; verificação da coerência interna dos trechos agrupados como similares; redação das categorias identificadas.

As categorias foram, por fim, analisadas com o apoio de bibliografia pertinente e em função dos objetivos do estudo.

\section{Resultados e discussão}

Com base nos relatos das participantes, foram escolhidos nomes fictícios para cada uma delas. Mais do que servir como modo de simples identificação, elegeram-se nomes que, por seu significado, resumiam de certo modo a história de cada mulher.

A seguir, faz-se breve apresentação de cada participante e dos conteúdos de suas entrevistas, organizados e discutidos em função dos temas mais relevantes.

\section{Vânia (do germânico: esperança, expectativa)}

18 anos, grávida de 25 semanas. Primípara, recebeu diagnóstico de soropositividade 5 meses antes da gestação, junto com o parceiro que também descobriu ser soropositivo na mesma ocasião. Esperançosos com o início da vida a dois, planejaram juntos a gravidez. O casal compartilha a certeza de que a contaminação ocorreu por via sexual, entre eles, mas não sabe dizer qual dos dois se contaminou antes.

\section{Alice (do fenício: protetora)}

28 anos, grávida de 28 semanas. Multípara, recebeu diagnóstico de soropositividade no pré-natal desta gestação ( $5^{a}$ da participante). Amasiada há cinco anos, relata que o parceiro se recusou a fazer a sorologia para HIV. A gravidez não foi planejada e surpreendeu o casal que se preparava para procedimento de esterilização definitiva (laqueadura). Ela preocupa-se em poder cuidar de todos os filhos: um com o parceiro atual e outros três de relacionamento anterior, sendo que os dois mais velhos ficaram no Maranhão com a avó materna. Alice não vê outra forma possível para sua contaminação além do contato sexual com o parceiro atual.

\section{Dolores (do latim: lamentações)}

28 anos, grávida de 24 semanas. Multípara, com diagnóstico há mais de 7 anos, relatou não ter contado a ninguém, nem ao pai do bebê em gestação. Em sua terceira gestação, ela afirma que "ia laquear e perdeu umas consultas"; depois, quando conseguiu reagen- dar o atendimento já estava grávida de novo. Largada durante a gestação pelo pai do bebê, ainda se declara amasiada porque o parceiro retorna de tempos em tempos para cobrar seus "direitos" como marido e sobre o barraco que ele ajudou a construir. Nas visitas que faz, ele também a agride verbal e fisicamente. Mãe de outros dois filhos, com companheiros diferentes, ela suspeita que seu primeiro marido, pai de um menino que já morreu, foi quem a contaminou.

\section{Lia (do hebraico: olhos tristes)}

29 anos, grávida de 36 semanas. Multípara, recebeu diagnóstico de soropositividade no pré-natal da gestação em curso. O parceiro fez o exame e descobriu que também é soropositivo. Amasiada, ela afirma que o parceiro tem a apoiado bastante, tentando encontrar a melhor forma para cuidar da saúde do bebê e garantir que ele seja um "bebê normal", sem problemas de imunidade que possam colocar sua sobrevivência em risco. A gravidez não foi planejada, mas foi bem recebida pelo casal. Mãe de um menino de 11 anos, do seu primeiro casamento, Lia tem dúvida em relação à forma de sua contaminação, oscilando entre o primeiro marido e seu vício em drogas, e o marido atual, que antes de se casar com ela teve várias mulheres e nem sempre usou preservativo.

\section{Amélia (do francês: sofredora, cúmplice)}

24 anos, grávida de 8 semanas. Multípara, descobriu sua soropositividade ao HIV há três anos, durante o pré-natal de sua primeira gestação. Mãe de dois meninos, relata que o marido não quis fazer o teste sorológico para HIV e disse que o filho não era dele. Na gravidez do segundo filho e nesta, atual, a história se repetiu e ele continua a dizer que os filhos não são dele, embora sustente a todos. Amélia diz que pensava em operar para não ter mais filhos, mas perdeu a consulta e o anticoncepcional de adesivo que usava "perdeu o efeito". Declara-se solteira há dois anos, desde que se separou legalmente do marido e pai de todos os seus filhos, mas diz que sempre reata com o ex-marido porque é ele quem paga as contas e também porque os filhos sentem a falta do pai. Tem certeza que foi contaminada pelo parceiro.

\section{Lara (do grego: deusa do silêncio eterno)}

37 anos, grávida de 34 semanas. Multípara, recebeu diagnóstico de soropositividade no pré-natal desta que é sua quinta gestação. Solteira desde que se 
separou do namorado, pai do bebê em gestação, Lara não revela se tinha conhecimento sobre o estado sorológico do parceiro. Moradora de "um ovo de cidade" no interior de São Paulo, afirma ter certeza que se contaminou por via sexual, mas não sabe dizer de qual dos seus parceiros. Teme o preconceito e deseja manter o diagnóstico em absoluto sigilo.

\section{Vera (do latim: verdadeira)}

28 anos, grávida de 8 semanas. Primípara, recebeu diagnóstico cerca de 1 ano antes da gestação, em exames de rotina. Na ocasião, o marido também realizou o exame e foi constatado que era soronegativo. O casal planejou a gestação, buscando informações sobre os riscos e as chances de evitar a contaminação do bebê. Foi contaminada pelo ex-noivo, que mantinha relações sexuais com outras mulheres sob seu consentimento, uma vez que ela se considerava "insuficiente para fazê-lo feliz".

\section{Carolina (do teutônico: aquela que éforte)}

31 anos, grávida de 12 semanas. Multípara, recebeu diagnóstico de soropositividade no pré-natal da gestação em curso. Amasiada, afirma que o parceiro se esquiva de fazer a sorologia para HIV afirmando que os exames "vão dar negativo". Em seu terceiro relacionamento estável, tem uma filha do primeiro casamento, já com 14 anos. A gestação atual não foi planejada, até porque o parceiro afirmava que tinha feito exames que o declaravam estéril. Além disso, ela nunca se esqueceu da dor do primeiro parto e não queria repetir a experiência. Ela não tem certeza de quem a contaminou: o primeiro marido, pai de sua filha; o segundo, com quem tinha uma relação estável e, por isso, transava sem camisinha; ou se este terceiro, que colocou como condição para o relacionamento a prática sexual sem preservativo.

\section{Andressa (do latim: corajosa)}

39 anos, grávida de 16 semanas. Multípara, sabe do diagnóstico de soropositividade há mais de 12 anos quando, ainda universitária, fez uma brincadeira com as amigas de faculdade para saber como era fazer o teste. O diagnóstico, anterior a suas gestações (esta e uma anterior, há dois anos), foi informado ao parceiro com quem vive em união estável há mais de 5 anos no início do relacionamento. Ela pediu que ele fizesse a sorologia, cujo resultado confirmou que ele era soronegativo. A primeira gestação aconteceu "no susto", quando o preservativo estourou; a gestação em curso também não foi planejada e aconteceu "sem querer". Ela tem certeza que foi contaminada por um ex-namorado.

\section{Vanessa (do latim: transformação)}

29 anos, grávida de 12 semanas. Primípara, recebeu diagnóstico de soropositividade no pré-natal. Amasiada, ela afirma que o parceiro não fala sobre a possibilidade de realizar a sorologia, mas não demonstrou espanto quando ela contou a ele sobre o diagnóstico. Ela entende que ele já sabe que é soropositivo e não quer confirmar que a contaminou. Ela, que nem teve namorados antes dele, não se conforma porque nunca "fez por onde" para "pegar" uma coisa assim e afirma que só pode ter sido contaminada por ele mesmo.

\section{Descoberta do diagnóstico e maternidade}

Das dez participantes incluídas no estudo, cinco já tinham conhecimento do diagnóstico de soropositividade ao HIV antes da gestação em curso no momento do estudo; as outras cinco receberam o diagnóstico durante o pré-natal da gestação em curso.

Dentre as mulheres que já conheciam o diagnóstico antes da gestação em curso, duas eram primíparas (Vânia e Vera) e declararam-se envolvidas em relacionamento estável (amasiada e casada, respectivamente e em suas palavras), afirmando ter planejado a gestação. Outras três participantes (Dolores, Amélia e Andressa) eram multíparas; duas declararam-se envolvidas em relacionamento estável (Dolores e Andressa, amasiada e em união estável, em suas palavras) e afirmaram não ter planejado a gestação, relatando inclusive o uso de métodos anticoncepcionais e o planejamento para realização de esterilização definitiva (laqueadura), Amélia, embora relate situação de convívio frequente com parceiro único, pai de seus filhos e do bebê em gestação, declara-se solteira, mas com absoluta dependência financeira deste parceiro.

Dentre as cinco mulheres que receberam o diagnóstico durante a gestação em curso no momento do estudo, apenas uma era primípara (Vanessa). Ela declarou-se solteira (embora tenha relatado situação de coabitação com parceiro único e pai do bebê em gestação) e relatou não ter planejado a gravidez. As outras participantes (Alice, Lia, Lara e Carolina), multíparas, declararam não ter planejado a gestação em 
curso e também citaram o uso de métodos anticoncepcionais ou o planejamento para realização de esterilização definitiva (laqueadura). Destas mulheres, três declararam-se amasiadas e uma solteira (Lara).

Analisando as motivações (ou determinantes) que ajudam a compreender a decisão de ter ou não filhos, observa-se a recorrência de um relato na fala de muitas mulheres que justificam a decisão de engravidar com base no desejo de dar filhos ao parceiro, assumindo assim seu esperado papel de mãe; além disso, elas relatam que o uso de preservativo nas relações sexuais é uma "interdição silenciosa" a este compromisso (de dar filhos ao parceiro). Assim, considerando as próprias práticas sexuais como produto de um roteiro socialmente estabelecido e aprendido, estas mulheres encontram dificuldades para exigir o uso de preservativo nas relações com seus parceiros, mesmo quando já conhecem o seu estado sorológico ou o do parceiro, o que dificulta o exercício de práticas preventivas nestes contextos (Silva et al., 2006).

Carvalho e Piccinini (2008) reforçam que há uma expectativa social de que a mulher assuma seu papel de mãe. Os autores sugerem ainda que a maternidade pode "santificar" a figura das mulheres, afastando-as da figura da prostituta, que inclui na vivência da sexualidade a dimensão da negociação, seja em termos de valor pelo serviço prestado ou ao considerar a proteção contra doenças sexualmente transmissíveis (DSTs) através do uso de preservativo.

Para as mulheres soropositivas e para os portadores de HIV de modo geral, a estigmatização pode produzir o que Goffman (1988) chama de "deterioração da identidade", considerando o assujeitamento destes indivíduos às respostas sociais de culpabilização e exclusão a partir do contágio por HIV.

A ideia do "compromisso feminino" em dar filhos ao parceiro parece reforçada pelos dados, que indicam que as participantes sem filhos e já cientes do seu diagnóstico de soropositividade ao HIV (Vânia e Vera) foram aquelas empenhadas em planejar a gravidez. $\mathrm{O}$ choque pela descoberta recente da soropositividade, na primeira gestação, pode justificar o relato de Andressa, que afirma não ter planejado a gestação revelando grande mágoa em relação ao parceiro. Tal percepção pode ser reforçada pelo fato da participante declarar-se solteira, embora viva junto a este parceiro.

Assim, o planejamento da gestação parece transcender a condição sorológica e o desejo por ter ou não (mais) filhos se fundamenta não no diagnóstico, mas em outros aspectos da vida e da relação conjugal.

\section{Forma de contaminação}

Para a contextualização e compreensão dos sentidos construídos pelas participantes, é importante observar suas referências quanto à forma (sabida ou presumida) de contaminação pelo HIV. Para muitas, a contaminação pelo parceiro reforça sua condição de submissão na relação conjugal, o que promove sentimentos ambivalentes: ora elas se veem como vítimas destes parceiros (ou ex-parceiros) e passam a requerer, assim, reparação afetiva ou financeira (Amélia); em outras situações, contudo, elas próprias se descrevem como corresponsáveis pela contaminação (Vera e Andressa) e passam a questionar a forma como se relacionam com o parceiro e com outras pessoas o que, pode, às vezes, servir como convite a uma revisão do próprio lugar nas relações sociais e conjugais/afetivas em que se envolvem.

Todas as participantes acreditam ter sido contaminadas por via sexual, em relacionamento com um parceiro único e fixo. Três avaliam a possibilidade de ter sido contaminadas pelo parceiro atual (Alice, Lia e Vanessa) e outra por um parceiro anterior (Dolores). Duas participantes afirmaram categoricamente terem sido contaminadas por parceiro anterior (Vera e Andressa) e outras duas pelo parceiro atual (Vânia e Amélia). Por fim, duas participantes disseram não poder precisar se a contaminação se deu no relacionamento atual ou em um anterior (Lara e Carolina).

Nascimento et al. (2005) apontam que o casamento é identificado pelas mulheres como um fator de proteção para a infecção por HIV, sugerindo uma baixa percepção do risco (Santos, Barbosa \& Pinho, 2009), o que determina que a Aids continue a ser conceituada como uma doença dos outros.

À exceção do que relata Andressa, a negociação do uso de preservativo é claramente negligenciada pelas mulheres envolvidas em relações estáveis que, embora conheçam os riscos assumidos na relação sexual desprotegida, parecem acreditar em uma espécie de "imunidade" presumida nas relações estáveis (Fioroni, 2005; Nascimento et al., 2005; Parker, 1995).

Vera e Carolina, por exemplo, relatam situações em que abriram mão do uso do preservativo em função do desejo de seus parceiros ou em razão da preocupação em agradá-los. 


\section{Vivência das relações conjugais e afetivas: a sorologia do parceiro como exemplo}

Apenas quatro participantes conheciam a situação sorológica do parceiro atual (Vânia, Lia, Vera e Andressa). Dentre estas quatro mulheres, duas viviam com parceiros também soropositivos ao HIV (Vânia e Lia) e relataram que o diagnóstico deles foi realizado logo após o delas, durante o pré-natal da gestação em curso, como investigação complementar. Estas duas participantes relataram bom relacionamento com os parceiros e afirmaram receber apoio deles tanto para o enfrentamento do diagnóstico quanto para a vivência da gestação.

As outras duas participantes que conheciam a situação sorológica dos parceiros, viviam com homens soronegativos ao HIV (Vera e Andressa). No caso de Andressa, o diagnóstico era conhecido há mais de 12 anos e o parceiro havia sido informado sobre sua condição desde o início do relacionamento. Juntos há mais de cinco anos, ambos já tinham uma filha com dois anos, fruto de "um acidente com uma camisinha estourada”. A participante relata que a gestação atual não foi planejada por medo da possibilidade de contaminação do bebê, mesma angústia da gestação anterior. No caso da outra participante cujo parceiro é soronegativo (Vera), a descoberta do diagnóstico ocorreu após o início do relacionamento deles, mas antes da gestação em curso, em exames de rotina. A participante relatou que o parceiro realizou testagem sorológica que confirmou que ele não estava contaminado pelo HIV e afirmou que o planejamento da gestação foi feito pelo casal, que buscou informações quanto aos riscos e às chances de evitar a contaminação do bebê durante o período gestacional. Nestes dois casos, as mulheres afirmaram dispor de apoio tanto para o enfrentamento do diagnóstico de soropositividade quanto para a vivência da gestação.

As outras seis participantes afirmaram desconhecer a situação sorológica de seus parceiros. Dentre estas mulheres, uma afirmou não ter revelado ao parceiro que é soropositiva (Dolores), desconhecendo também a situação sorológica dele; as outras cinco relataram que os parceiros se recusaram a realizar a testagem sorológica para saber se eram ou não soropositivos ao HIV (Alice, Amélia, Lara, Carolina e Vanessa).

A participante que disse não ter revelado sua situação sorológica ao parceiro, apesar da interven- ção dos profissionais de saúde que a acompanhavam em uma Unidade de Saúde da Família, afirmou que o parceiro, muito agressivo e violento, a abandonou e mudou de cidade, voltando para sua terra natal em outro Estado. Esta participante diz não ter qualquer apoio familiar, emocional ou financeiro.

Três das participantes (Alice, Amélia e Carolina) que também relataram desconhecer a situação sorológica de seus parceiros contaram que eles se mostraram contrários à realização da testagem sorológica por considerarem que era desnecessária. As mulheres entenderam que, na verdade, todos já se sabiam soropositivos e temiam ter que revelar sua condição para as parceiras. As outras duas mulheres (Lara e Vanessa) afirmaram, por fim, que seus parceiros agiram com o silêncio ante a perspectiva de realização da testagem sorológica "fingindo que não era com ele", como relatou uma das participantes. Estas duas participantes também entenderam o silêncio dos parceiros como uma confirmação de seu conhecimento anterior em relação à própria soropositividade.

Fioroni (2005) discute a transmissão do HIV em relações heterossexuais abordando a vivência da sexualidade, inclusive em experiências extraconjugais, como elemento de desestruturação da concepção romantizada do relacionamento conjugal. O impacto desta desestruturação aparece nos relatos das participantes, que apontam a necessidade de descobrir qual a responsabilidade dos parceiros em sua contaminação. Parece haver uma maior valorização da forma de contaminação destes homens do que propriamente uma tentativa de explicar o contágio. Como "vítimas" da ação destes homens, parece haver o desejo de saber se há ou houve um "dano acumulado", representado pela traição do parceiro.

\section{Considerações finais}

A expectativa deste artigo é contribuir para a análise da situação feminina, com ênfase nas contingências enfrentadas por mulheres soropositivas ao HIV, propondo uma discussão sobre a responsabilidade e o desenvolvimento da autonomia como alternativas à vitimização.

Além disso, pretende-se chamar para a necessidade de que psicólogos que atuam em serviços de saúde pública, principalmente naqueles que integram a Atenção Primária à Saúde, desenvolvam estratégias de atenção a mulheres com foco na discussão de seus direitos. 
Este estudo mostrou, a partir da descrição que fazem de si mesmas como esposas, namoradas, parceiras sexuais, filhas e mães, que as mulheres entrevistadas relatam quem são colocando-se, claramente, como seres em função dos homens com quem se relacionam e das estratégias com as quais lidam com a soropositividade, muitas vezes "produzida" na relação com estes (ou outros) parceiros.

Obviamente, não se espera que os psicólogos, isoladamente, sejam capazes de desenvolver o tipo de intervenção aqui sugerida, mas acredita-se que pode partir deste profissional (fundamentado em sua capacidade crítica e transformadora) uma proposta de sensibilização de outros membros das equipes de saúde para que, juntos, possam promover exercício de reconhecimento do poder destas mulheres.

Como exemplo, sugerir que as gestantes soropositivas mantenham o vínculo com a unidade de saúde de origem, ao invés de serem compulsoriamente "encaminhadas" e exiladas em serviços de referência, já pode ser definido como ganho para a equipe e sobretudo para estas mulheres. Ajudar a equipe de saúde a reconhecer as possibilidades de produção de cuidado com estas mulheres, para além das questões meramente técnicas (pertinentes exclusivamente ao campo da ginecologia, obstetrícia, infectologia etc.) também é alternativa de trabalho negligenciada por muitos profissionais da Psicologia.

Entre as participantes do estudo são muitos os sentimentos experimentados: esperança pelas possibilidades de uma história conjugal que se inicia (Vânia), angústia com a perspectiva de impossibilidade de cuidado com os filhos (Alice), revolta com a agressividade e desrespeito do parceiro (Dolores), ilusão com a inocência do parceiro (Lia), apatia pela falta de perspectivas (Amélia), medo do preconceito (Lara), desejo de revelação e liberdade (Vera), aceitação (Carolina), culpa (Andressa) e revolta (Vanessa).

Depois de olharem para si, através de quem são para os homens ou para o HIV, as participantes puderam olhar para quem se tornaram enquanto mães. O medo pela própria morte e pela impossibilidade em cuidar dos filhos apareceu com força nos relatos do estudo realizado e aspectos da vivência de culpa pelo próprio contágio ou pela possibilidade de infectar aos filhos também permearam essa descoberta de como posicionar-se diante deste "novo" papel para as mulheres: o de mães.
Ao longo destes relatos e em um processo integrado, que comporta elementos de clareza e confusão, essas mulheres foram se redescobrindo como seres integrais, completos na ambivalência de seus sentimentos.

A versão que as define enquanto indivíduos submetidos ao desejo masculino é histórica, exaustivamente repetida e inequívoca, sobretudo em sociedades machistas como as latino-americanas, mas é também processual, fluida como a vida e as relações que se desenrolam diariamente entre as pessoas e, exatamente por isso, sujeita a revisões e mudanças.

Em relação à submissão que se constrói para e pelas mulheres, Fioroni (2005) pontua que a expropriação do poder das mulheres em relação ao próprio corpo e sexualidade reforçam este processo.

Como atuar, então, na recuperação do poder sobre si mesma? Como ajudar estas mulheres a se reencontrarem como "senhoras de si", considerando aqui o poder sobre seus corpos, mentes e afeto? Certamente uma intervenção protocolar não será suficiente, uma vez que não se trata de "ensinar" sobre poder e autoestima; trata-se de proporcionar a vivência deste poder, sugerindo e acompanhando cada uma destas mulheres em seu percurso próprio para recuperar a si mesmas das mãos dos outros.

Em muitas situações, os filhos (e o poder de gerá-los - tão exclusivo das mulheres) parecem surgir como elemento deste poder. É através dos filhos que elas conquistam definitivamente a identidade de mulheres (e não mais meninas) e passam a "ser donas da própria vida”. É também a partir dos filhos que pensam em retribuir o amor, predileção ou o desejo dos parceiros - isso sobretudo quando elas são soropositivas ao HIV e eles não.

Mas a maternidade nem sempre é uma escolha de poder; na maioria das vezes, simplesmente acontece - como o próprio contágio por HIV - pela vontade e desejo do outro. A questão sexual e reprodutiva aparece com força neste estudo, uma vez que todas as participantes se contaminaram por via sexual.

Vulneráveis e passivas por imposição de uma relação de gênero historicamente pautada, que determina o que serão em função da necessidade masculina, as mulheres vivem a maternidade compulsória, a sujeição à infidelidade dos parceiros, a dependência financeira e afetiva como algumas das formas de nomear esta dominação e de construir sua vulnerabilidade. 
Há que se considerar, no entanto, que, enquanto sujeitos deste processo, cada uma destas mulheres tem, ao menos em tese, a possibilidade de atuar no sentido de refazer, renomear e reconstruir sua própria história e sua própria descrição. Não se pretende apelar aqui para uma proposta que responsabilize cada indivíduo, isoladamente, pela transformação de suas condições de vida, uma vez que a materialidade desta questão se impõe como determinante de limites concretos, mas sugere-se a necessidade de apropriação em relação à vida e às contingências que a compõem.

Romper com a perspectiva de si mesmas enquanto vítimas passivas da ação dos homens e assumir a possibilidade de atuar como protagonistas de sua história são desafios que se impõem como prerrogativas mínimas para a superação da fragilidade a que estão expostas as mulheres em relação ao HIV.

Mais que uma questão ideológica, buscar para si um lugar de resistência à dominação masculina é um desafio pessoal, de constituição da própria identidade e de afirmação para si de um lugar social diferente.

Em linhas gerais, parece correto afirmar que a promoção da apropriação das mulheres em relação à sua história (inclusive à sua história de contágio por HIV) deve começar por um processo de fortalecimento da autoestima e da autoimagem feminina enquanto seres de direito e valor.

Nos casos em que perdura o preconceito e a desvalorização das mulheres em relação a si próprias e quando isso faz com que perseverem as condições para a dominação masculina, certamente haverá maiores dificuldades para que se conquiste condições mínimas para a proteção das mulheres.

Cabe avaliar e respeitar, entretanto, de que forma as próprias mulheres são capazes de considerar estas dimensões para requalificar sua posição na sociedade e nas relações bem como considerar quais são as estratégias que podem ser incorporadas ao repertório de ações em saúde para que essa transformação possa encontrar bases de apoio mínimas para se processar.

Fazer com que a mulher se reconheça com agente de sua própria sexualidade, como sujeito com desejos e capacidade de escolha quanto a como viver e satisfazer esses desejos, é um primeiro passo para que seja possível construir uma identidade sexual e de desejo integradas. Neste contexto, a construção das condições afetivas e cognitivas para o uso de preservativo nas relações sexuais e o estímulo para que as mulheres se envolvam ativamente no processo de planejamento familiar são algumas das possibilidades que podem orientar o trabalho de equipes de saúde.

Reconhecendo-se como indivíduos que merecem respeito e cuidado, é possível dar a estas mulheres recursos para identificar, nas relações de gênero e familiares em que se envolvem, os elementos que desqualificam a mulher para que, assim, possam opor resistência a eles como estratégia positiva no sentido de garantir sua integridade enquanto sujeitos.

Ações ou programas de qualificação profissional e de desenvolvimento de habilidades entre as mulheres, para que elas se reconheçam enquanto sujeitos de valor e poder econômico são outra possibilidade a ser analisada. Autossuficientes financeiramente e detentoras de condições econômicas mínimas para garantir o bem-estar próprio e dos filhos, as mulheres podem assumir o poder de decisão pelo futuro familiar, rompendo a dominação e sujeição aos homens.

Há que se pontuar, contudo, que, embora historicamente associados à ideia da dominação, os homens não podem ser apontados como culpados pela submissão feminina, devendo ser creditada também às mulheres responsabilidade pela aceitação tácita das exigências masculinas e a construção conjunta das bases materiais para a história da dominação.

Compreender e assumir esta responsabilidade é ponto fundamental para a construção de um outro modo de levarem a vida e de serem sujeitos completos, não fragmentados pela submissão.

\section{Referências}

Brasil. (2015). Ministério da Saúde. Coordenação Nacional de DST/Aids. Boletim epidemiológico de Aids. Brasília, DF: o autor. Recuperado de htpp://www.aids.gov.br/sites/default/files/anexos/publicacao/2015/58534/boletim_aids_11_2015_web_pdf_19105.pdf

Brasil. (2004). Ministério da Saúde. Secretaria de Atenção à Saúde. Política nacional de atenção integral à saúde da mulher: princípios e diretrizes. Brasília, DF. Recuperado de http://conselho.saude.gov.br/ultimas_noticias/2007/ politica_mulher.pdf. Acesso em 13/12/2016. 
Cantele, J., Arpini, D. M., \& Roso, A. (2012). A Psicologia no modelo atual de atenção em saúde mental. Psicologia: Ciência e Profissão, 32(4), 910-925. cienc. prof. [online]. 2012, vol.32, n.4, pp.910-925. https://doi.org/10.1590/ S1414-98932012000400011

Carvalho, F. T., \& Piccinini, C. A. (2008). Aspectos históricos do feminino e do maternal e a infecção pelo HIV em mulheres. Ciência \& Saúde Coletiva, 13(6), 1889-1898. https://doi.org/10.1590/S1413-81232008000600024

Figueiredo, R. M. (2003). Cuidadores de pacientes com Aids: atos assistenciais. In: E.R. Turato (Org.), Psicologia da saúde: estudos clínico-qualitativos (pp. 257-271). Taubaté: Cabral.

Fioroni, L. N. (2005). Vulnerabilidade feminina e a construção de significados sobre a maternidade em mulheres portadoras do HIV (Tese de doutorado). Faculdade de Filosofia, Ciências e Letras de Ribeirão Preto, Universidade de São Paulo, Ribeirão Preto, SP.

Goffman, E. (1998). Estigma: notas sobre a manipulação da identidade deteriorada. Rio de Janeiro, RJ: Guanabara.

Guareschi, N. M. F., Dhein, G., Reis, C., Machry, D., \& Bennemann, T. (2009). A formação em Psicologia e o profissional da Saúde para o SUS (Sistema Único de Saúde). Arquivos Brasileiro de Psicologia, 61(3), 35-45. Recuperado de http://pepsic.bvsalud.org/pdf/arbp/v61n3/v61n3a05.pdf

Lamoglia, C. V. A., \& Minayo, M. C. S. (2009).Violência conjugal, um problema social e de saúde pública: estudo em uma delegacia do interior do Estado do Rio de Janeiro. Ciência \& Saúde Coletiva, 14(2), 595-601.

Nascimento, A.M.G., Barbosa, C.S., \& Medrado, B. (2005). Mulheres de Camaragibe: representação social sobre a vulnerabilidade feminina em tempos de AIDS. Rev Bras Saúde Materno Infantil, 5(1), 77-86. https://doi. org/10.1590/S1519-38292005000100010

Parker, R.G. (1995). A construção social e cultural do risco sexual, ou como fazer pesquisa (em sexualidade) em uma epidemia. Physis, Revista de Saúde Coletiva, 5(1), 85-98. https://doi.org/10.1590/S0103-73311995000100004

Parker, R.G. (1997). Reflexões sobre a sexualidade na sociedade Latino-Americana: implicações para intervenções em face do HIV/Aids. Physis, Revista de Saúde Coletiva, 7(1), 99-108. https:// doi.org/10.1590/S010373311997000100005

Parker, R., \& Camargo, K. R. (2000). Pobreza e HIV/Aids: aspectos antropológicos e sociológicos. Cadernos de Saúde Pública, 16(supl 1), 89-102. https://doi.org/10.1590/S0102-311X2000000700008

Parker, R. G., \& Aggleton, P. (2001). Estigma, discriminação e aids (Coleção ABIA. Cidadania e Direitos, vol. 1). Rio de Janeiro, RJ: Associação Brasileira Interdisciplinar de Aids.

Ribeiro, K. C. S., Silva, J., \& Saldanha, A. A. W. (2011). Querer é poder? A ausência do uso do preservativo nos relatos de mulheres jovens. Jornal Brasileiro de Doenças Sexualmente Transmissiveis, 23, 84-89.

Sales, A. L. L. F., \& Dimenstein, M. (2009). Psicólogos no processo de reforma psiquiátrica: práticas em desconstrução?. Psicologia em Estudo, 14(2), 277-285. https://doi.org/10.1590/S1413-73722009000200008

Santos, N. J. S. (1998). Características sociais, risco e ocupação nas mulheres com Aids em São Paulo. Atualidade em DST/Aids, 1(2), 39-53.

Santos, N. J. S., Barbosa, R. M., \& Pinho, A. (2009). Contextos de vulnerabilidade para o HIV entre mulheres brasileiras. Cadernos de Saúde Pública, 25(supl 2), S321-S333. https://doi.org/10.1590/S0102-311X2009001400014

Silva, N. E. K., Alvarenga, A. T., \& Ayres, J. R. C. M. (2006). Aids e gravidez: os sentidos do risco e o desafio do cuidado. Revista de Saúde Pública, 40(3), 474-481. https:// doi.org/10.1590/S0034-89102006000300016

Villela, W. V., \& Monteiro, S. (2015). Gênero, estigma e saúde: reflexões a partir da prostituição, do aborto e do HIV/aids entre mulheres. Epidemiologia e Serviços de Saúde, 24(3), 531-540. https://doi.org/10.5123/S167949742015000300019

\section{Marina Simões Flório Ferreira Bertagnoli}

Faculdade de Filosofia, Ciências e Letras de Ribeirão Preto (FFCLRP), Departamento de Psicologia da Universidade de São Paulo, São Paulo - SP. Brasil.

E-mail: marinasimoes@ffclrp.usp.br 


\section{Marco Antônio Castro Figueiredo}

Faculdade de Filosofia, Ciências e Letras de Ribeirão Preto (FFCLRP), Departamento de Psicologia da Universidade de São Paulo, São Paulo - SP. Brasil.

E-mail: msimoesff@gmail.com

Endereço para envio de correspondência:

Faculdade de Filosofia, Ciências e Letras de Ribeirão Preto - USP

Departamento de Psicologia, Bloco 5 (CPA), Sala 1

Av. Bandeirantes, 3900

Ribeirão Preto-SP, Brasil

CEP: 14040-901

Telefone: (16) 33153786

Recebido 14/12/2016

Aprovado 20/10/2017

Received 12/14/2016

Approved 10/20/2017

Recibido $14 / 12 / 2016$

Aceptado 20/10/2017

Financiamento: Coordenação de Aperfeiçoamento de Pessoal de Nível Superior (Capes).

Como citar: Bertagnoli, M. S. F. F., \& Figueiredo, M. A. C. (2017). Gestantes soropositivas ao HIV: maternidade, relações conjugais e ações da Psicologia. Psicologia: Ciência e Profissão, 37(4), 981-994. https://doi.org/10.1590/1982-3703004522016

How to cite: Bertagnoli, M. S. F. F., \& Figueiredo, M. A. C. (2017). HIV-positive pregnant women: maternity, marital relationships and actions of Psychology. Psicologia: Ciência e Profissão, 37(4), 981-994. https://doi.org/10.1590/1982-3703004522016

Cómo citar: Bertagnoli, M. S. F. F., \& Figueiredo, M. A. C. (2017). Las mujeres embarazadas que viven con el VIH: la maternidad, las relaciones maritales y acciones de Psicología. Psicologia: Ciência e Profissão, 37(4), 981-994. https://doi.org/10.1590/1982-3703004522016 